\title{
Urdimento
}

Revista de Estudos em Artes Cênicas

E-ISSN: 2358.6958

\section{O que acontece quando eu olho para você: o espaço íntimo do teatro na prisão}

Karen Hamer

Cedric Martin

\section{Para citar este artigo:}

HAMER, Karen; MARTIN, Cedric. O que acontece quando eu olho para você: o espaço íntimo do teatro na prisão. Urdimento, Florianópolis, v. 3, n. 39, nov./dez. 2020. 


\title{
O que acontece quando eu olho para você: o espaço íntimo do teatro na prisão
}

Karen Hamer ${ }^{1}$, Cedric Martin²

Traduzido por Nícolas de Córdova Dorvalino e Túlio Fernandes Silveira ${ }^{3}$

\begin{abstract}
Resumo
Apesar dos crescentes estudos sobre teatro e voluntários em prisões, há pouca pesquisa que olha para a experiência teatral da prisão através dos olhos tanto dos voluntários externos quanto dos prisioneiros-participantes. Este artigo busca tecer as vozes coautorais para explorar experiências compartilhadas da sala de aula do teatro prisional. Essas experiências descritas como "mágicas" e "transcendentes" - dependem do voluntariado realizando atividades com sucesso na prisão. o espaço da sala de aula do teatro na prisão torna-se então um refúgio relacional onde tanto os presos quanto os voluntários podem se sentir bem-vindos e aceitos, vistos não como outros, mas como essenciais.
\end{abstract}

Palavras-chave: Teatro na prisão. Artes prisionais. Voluntários na prisão. Reabilitação. Artes em correções.

${ }^{1}$ Doutoranda na Universidade do Texas-Dallas (EUA). É fundadora e diretora artística da Tin Roof Productions 501(c)(3). Karen ensinou Shakespeare como voluntária na Instalação Correcional de Fremont, em Cañon City, Colorado, de 2015 a 2017. kxh200012@utdallas.edu karen.b.hamer@gmail.com

${ }^{2}$ Membro da Iniciativa de Artes Prisionais da Universidade de Denver, Colorado, EUA. Membro da DUPAI na Penitenciária Sterling, em Sterling, Colorado. Dos 20 anos de prisão, ele passou mais de dez anos na solitária. Os interesses de Cedric incluem matemática, física, escrita de cartas e edrawing.

${ }^{3}$ Tradução do inglês realizada por graduandos do curso de Licenciatura em Teatro da Universidade do Estado de Santa Catarina (UDESC) e bolsistas de pesquisa do programa "Teatro e prisão: práticas de infiltração das artes cênicas em espaços de vigilância", orientado pelo Dr. Vicente Concilio, professor do Departamento de Artes Cênicas da UDESC. Revisão da tradução deste artigo realizada pelo coordenador desse projeto. Este artigo também se encontra publicado em inglês neste mesmo periódico. 
What happens when I look at you: the intimate space of prison theater

\begin{abstract}
Despite the burgeoning literature on theater and volunteers in prisons, there is little research that looks at the prison theater experience through the eyes of both the outside volunteers and the prisoner-participants. This article seeks to weave together the voices of the co-authors in order to explore shared experiences of the prison theater classroom. These experiences - variously described as 'magical' and 'transcendent' - are dependent on the volunteer successfully navigating entry into the prison. The space of the prison theater classroom then becomes a relational refuge where both prisoners and volunteers can feel welcome and accepted, seen not as other but as essential.
\end{abstract}

Keywords: Prison theater. Prison arts. Prison volunteers. Rehabilitation. Arts-incorrections.

\title{
Que pasa cuando te miro: el espacio de teatro íntimo en prisión
}

\section{Resumen}

A pesar de los crecientes estudios de voluntarios de teatro y prisiones, hay poca investigación que analice la experiencia teatral de la prisión a través de los ojos tanto de voluntarios externos como de prisioneros participantes. Este artículo busca tejer las voces de los coautores para explorar experiencias compartidas del aula de teatro carcelario. Estas experiencias, descritas como "mágicas" y "trascendentes", dependen de que el voluntariado navegue con éxito por la entrada de la prisión. El espacio del aula del teatro de la prisión se convierte entonces en un refugio relacional donde tanto los presos como los voluntarios pueden sentirse bienvenidos y aceptados, vistos no como otros, sino como esenciales.

Palabras clave: Teatro en prisión. Artes penitenciarias. Voluntarios en prisión. Rehabilitación. Artes de corrección. 
O que faz da arte em geral, e do teatro em particular, uma ferramenta terapêutica tão eficaz? Não posso professar que sei. O que posso dizer, com absoluta certeza, é que minha própria experiência com o mundo do teatro e os magníficos facilitadores desta inesperada panaceia tem fomentado o crescimento, o amadurecimento e a consciência como nenhuma outra coisa que já encontrei. Eu procurei por essas coisas durante todos os meus 20 anos de encarceramento - com mais de 10 anos de confinamento em uma solitária - sem sucesso. O que passei a acreditar foi que eles não existiam. Até encontrar meu primeiro voluntário de teatro. - Cedric Martin (escrito em confinamento solitário, setembro de 2020).

\section{Preparando a cena: tecendo autoetnografias}

Este artigo é uma coprodução entre autores cujos caminhos se cruzaram em uma sala de aula de Teatro na Prisão em uma unidade masculina no Colorado em 2016. É costurado a partir de autoetnografias distintas, porém conectadas, dos autores, a partir de seus e-mails e cartas, bem como de longas conversas com voluntários de Teatro nas Prisões no Reino Unido e em todos os EUA. É escrito especificamente como uma exploração da relação entre facilitadores ${ }^{4}$ do Teatro na Prisão e participantes encarcerados e, como tal, baseia-se em pesquisas originais que se concentram nas experiências dos voluntários.

$\mathrm{Na}$ necessidade de uma varredura introdutória e superficial deste terreno pouco pesquisado, este artigo leva em conta como os voluntários do Teatro na Prisão percorrem o acesso às prisões e como eles cruzam limites e constituem relacionamentos significativos dentro de espaços carcerários. Também escuta atentamente o tom do espaço relacional dentro do Teatro na Prisão, que pode afetar profundamente uma pessoa encarcerada com a experiência desorientadora de ser tratado como humano na prisão. Isso pode ter um impacto desarmador correspondente sobre os voluntários do Teatro. O objetivo geral dos autores e autoras é caminhar pela paisagem de uma parceria de escrita compartilhada que é negociada através dos muros da prisão. Esta abordagem experimental expõe o

${ }^{4}$ O termo "facilitador" nos Estados Unidos é utilizado para indicar pessoas não formadas em determinadas áreas, mas que ministram oficinas sobre esses conteúdos. 
estilo, processo e conteúdo da exploração.

\section{Como este artigo surgiu}

Parte do conteúdo deste artigo foi destilado por Cedric a partir de suas observações e experiências em aulas de teatro, em duas das vinte e duas prisões estaduais do Colorado, nos últimos quatro anos. Residente no Colorado Department of Corrections (CDOC) 5 desde os dezoito anos, Cedric é um artista que esteve envolvido no teatro nos últimos quatro anos. Ele elaborou suas primeiras reflexões para este artigo no final de um período de um ano na solitária.

Este período em particular na solitária foi uma punição por sua resposta violenta a um guarda que o provocou cruelmente logo após a morte da mãe de Cedric, no ano passado. Tal punição não era nova para Cedric; ele passou mais de dez de seus vinte anos no CDOC na "loucura" que é o confinamento solitário de longo prazo. De acordo com o regulamento da Covid-19, ele foi autorizado a sair de sua cela todos os dias para um banho de quinze minutos. O resto do tempo ele passou desenhando, lendo, estudando matemática, física, ouvindo música, trabalhando em sua escrita criativa: histórias, poesia e dramaturgia. Escreveu cartas articuladas e cuidadosas, argumentando uma linha de pensamento, perguntando em voz alta, registrando sua vida interna e externa, expressando preocupação. Parte do material deste artigo é extraído dessas cartas.

A outra parte do conteúdo deste artigo em conjunto foi coletada durante a pesquisa de pós-graduação de Karen em Applied Criminology and Penologyo no Instituto de Criminologia da Universidade de Cambridge. Como uma exploração das experiências de voluntários que executaram programas de Teatro nas Prisões dos EUA, a pesquisa de Karen também se baseou em sua própria experiência como voluntária de Teatro na Prisão no Colorado de 2015 a 2017. Karen estava particularmente interessada em identificar as habilidades relacionais necessárias

\footnotetext{
${ }^{5}$ Tradução: Departamento de Correções do Colorado

${ }^{6}$ Tradução: Criminologia Aplicada e Penologia
} 
para percorrer os regulamentos e limites da prisão - a fim de maximizar a liberdade de expressão física, vocal e emocional - em um ambiente punitivo dominado pela coerção, ordem e controle (Cheliotis, 2012).

Karen conduziu um estudo de métodos mistos que envolveu a análise de dados de setenta pesquisas devolvidas por facilitadores de Teatro na Prisão e a codificação de quase quatrocentas mil palavras, de mais de quarenta horas de entrevistas semiestruturadas, com vinte e cinco profissionais de teatro voluntários com sede nos EUA (Hamer, 2019). As vozes de Karen e Cedric são, assim, tecidas juntamente com as dos voluntários deste estudo, criando um círculo de compreensão cada vez maior em torno do fenômeno do Teatro na Prisão.

\section{Um convite para o autoquestionamento}

Em março de 2015, Karen recebeu um e-mail da bibliotecária de uma prisão masculina de segurança média, em Cañon City, Colorado, convidando-a para iniciar um programa de teatro semanal. Ela ficou imediatamente interessada, por já ter sido uma voluntária semanal em uma prisão da sua cidade natal, Auckland, Nova Zelândia. No entanto, Karen mal sabia que, como uma criança através de um guarda-roupa estranhamente encantado, ela estava prestes a entrar na "instituição total" (Goffman, 1961) de uma prisão estadual dos EUA, onde a maneira habitual de fazer sentido do mundo - de conversar, de andar, de raciocinar como uma pessoa "normal" - não importaria mais. Especificamente, o que ela ainda não sabia era que fazer teatro em uma prisão seria extraordinariamente desafiador, não por causa dos "intimidadores" criminosos, mas por causa do estômago faminto da própria prisão, pelo qual homens e mulheres foram engolidos como forragem para a "barriga da besta" (Abbott, 1978) - tanto prisioneiros quanto voluntários. Ela também ainda não sabia como isso seria bonito.

A construção de sentidos também viria mais tarde para Karen, em entrevistas e conversas com outros voluntários do teatro prisional e, eventualmente, em quase duzentas conversas baseadas em cartas com Cedric. Cedric já havia experimentado uma "descida à loucura", que caracterizou sua primeira estadia na 
solitária, por seis anos a partir de 2009. E ele tinha aprendido a entender a falta de sentido da prisão, a reagir violentamente quando necessário, a aprender a se importar menos. Em 2015, quando o convite da bibliotecária caiu inocentemente na caixa de entrada de Karen, tanto Cedric quanto Karen ainda estavam para descobrir que, na barriga da besta, é a natureza das relações entre participantes encarcerados e voluntários de teatro que se torna alimento para todos prisioneiros e voluntários - no espaço sagrado e íntimo que é o teatro na prisão.

\section{Por que escrever juntos?}

Para Cedric, fazia sentido dividir a autoria deste artigo com Karen porque sua relação se aprofundou em uma verdadeira amizade, que está mergulhada em amplo diálogo e respeito mútuos. As discussões pelas cartas trocadas entre Cedric e Karen se estendem como um acordeom pelos temas de criatividade, reabilitação, objetivos de vida, raça, morte e trauma, para citar alguns. Mesmo antes da oportunidade de coautoria deste artigo estar no horizonte, os autores discutiram sobre a dinâmica de poder que potencialmente estava em jogo em sua relação como um homem negro na prisão e uma mulher branca em um doutorado em uma universidade.

Em uma carta datada de 20 de agosto de 2020, Karen escreveu para Cedric:

Podemos ter essa discussão acerca do "poder"? Está em todo o país e em todo o mundo desde a morte de George Floyd. Eu não me sairia bem, eu suspeito, em uma dissecação do nosso relacionamento... uma mulher branca de classe média (muito menos uma mulher cristã) escrevendo para um homem negro na prisão, enviando-lhe livros, enviando-lhe torrentes de palavras... isso seria difícil de defender no tribunal da opinião pública atual. Eu seria uma supremacista branca e você, um negro oprimido. É assim que as pessoas são? Ou pode haver outras camadas de análise...?

Em uma carta datada de 25 de agosto de 2020, Cedric escreveu para Karen:

Desde a morte de George Floyd, você está certa, há muitas opiniões 
sendo arremessadas lá fora. Há a noção de uma mulher branca se armando e orquestrando a erradicação do homem negro. Há vídeos de celulares de homens negros ricos sendo acusados e abordados por mulheres brancas e, em seguida, vilanizados e vitimados. Não há nada disso em nosso relacionamento. Você não está me oprimindo, me doutrinando, me incomodando e eu não poderia me importar menos com o que um estranho pensaria. Eu tenho uma opinião sobre cada aspecto desta incidentes que abalaram nações. Acredito que haja racismo sistêmico. Acredito que fui vítima disso. Acho que não há nada disso aqui [entre nós].

Apesar de uma avaliação negativa de um dos conhecidos de Cedric, que pintou Karen como necessariamente uma "supremacista branca" que procurou posicionar Cedric como "um cavalo de Troia, perfeitamente posicionado para oprimir [seu] povo", Cedric nega essa caracterização de seu relacionamento com ela, alegando, com um senso de desprendimento, que ele "não poderia se importar menos com o que um estranho pensaria". Nesse sentido, os autores buscam um desprendimento engajado em sua relação de trabalho que não nega a especificidade histórica de sua parceria, como homem negro encarcerado e mulher branca situada na universidade, nem permite que essas categorias redutivas reivindiquem uma definição abrangente ou exclusiva.

Por meio de interrogatório mútuo - um do outro, e sua parceria de trabalho - os autores buscam ser autoconscientes e não ingênuos sobre a natureza de suas relações. Apesar do racismo sistêmico do sistema prisional que ambos concordam existir, e que Cedric foi sujeito, ele afirma que não é "oprimido", "doutrinado", ou "incomodado" por sua parceria com Karen. Ele tem suas próprias opiniões que não estão sujeitas nem a sua aprovação nem acordo, nem a de ninguém, e ela retribui o favor. O acordo deles é um engajamento autorreflexivo que é intencionalmente tecido, na medida do possível, como uma parceria "aninhada" não hierárquica (Fouché e Lunt, 2010) entre os autores.

\section{Como este artigo foi escrito}

Este artigo foi concebido como um desejo de escrever de forma equitativa e 
colaborativa, com vozes equilibradas, através das barreiras estruturais tanto da prisão quanto da academia. Como instituições e burocracias que surgiram em suas formas atuais ao longo de cronogramas semelhantes, a prisão e a universidade têm uma série de semelhanças, especialmente em suas funções de classificação, rotulagem e replicação.

Este artigo nasceu na realidade de navegar em barreiras operacionais internacionalmente e em meio ao fluxo e transição. Em circunstâncias habituais, Karen poderia se corresponder com Cedric pelo e-mail jpay.com, o sistema de email da prisão. Uma cópia impressa do e-mail seria inserida através de uma fenda na cela de Cedric e cairia no chão poucas horas depois de ser despachada. Dependendo do tempo que Cedric levou para escrever uma resposta dependendo de quão longa ou curta sua carta era, bem como de qual era sua cota de selos para a semana, e de quando sua correspondência foi coletada - uma carta que foi postada na quinta-feira no Colorado poderia estar na caixa postal de Karen no Texas na segunda-feira às 11:30. O tempo era tudo para uma rápida e suave troca de palavras e ideias. O primeiro rascunho do artigo foi escrito desta forma.

A fase de revisão do artigo coincidiu com a mudança de Cedric para uma outra prisão no Colorado para iniciar um processo de progressão penal oferecido população prisional geral. No mesmo dia em que ele estava em transição entre espaços carcerários, Karen estava voando de Fort Worth, Texas, para Auckland, Nova Zelândia. Ao desembarcar no Aeroporto Internacional de Auckland, ela foi colocada em um local de isolamento gerenciado pelo governo por catorze dias, antes de se reunir com sua irmã mais nova, que recentemente recebeu inesperadamente um diagnóstico de câncer em estágio quatro. De repente, em uma fase chave do processo de escrita colaborativa de Cedric e Karen, havia mais partes complicadas e em movimento do que o normal. O correio internacional não era uma opção porque os prazos eram apertados.

Cedric imediatamente criou um caminho elegante para tornar possível navegar pelos espaços liminais paralelos (Turner, 2012) que ele e Karen estavam ocupando agora. Ao fazer seu irmão gravar as rápidas palavras de Cedric pelo 
telefone - você tem trinta segundos restantes! - e enviá-los para Karen, os autores foram capazes de circunavegar efetivamente o globo, diminuindo a distância em dezenove fusos horários, a fim de cumprir seu compromisso de escrever juntos. Karen transcreveu as palavras de Cedric e as enviou de volta para ele via jpay.com para mais comentários. Quatro gravações foram gerenciadas desta forma em meio a um sistema de gravação temperamental e acessibilidade limitada do telefone. Muita paciência para suportar os desafios de seus ambientes de escrita, respeito mútuo que proporcionou diálogo aberto, confiança profunda que possibilitou uma conversa honesta e uma visão compartilhada para contar uma história compartilhada em um documento escrito foram os múltiplos motores que mantiveram a parceria em movimento.

\section{Contexto: a geografia das prisões e dos voluntários da prisão}

Há uma geografia forte e específica para o teatro na prisão nos EUA. No mundo pré-Covid, voluntários de teatro dos EUA executaram programas em uma variedade de ambientes prisionais, de cadeias a prisões estaduais, embora alguns resistam à nomenclatura do "programa" como serviço aos objetivos da instituição (Fesette e Levitt, 2017). Os programas normalmente acontecem em ambientes de segurança média ou média-alta, e são realizados em estabelecimentos prisionais para homens, mulheres e jovens. Oitenta por cento dos programas de teatro nas prisões nos EUA, em 2018, ocorreram em prisões masculinas, com mulheres liderando dois terços dos programas teatrais em instalações prisionais masculinas e praticantes homens executando quase três quintos de programas de teatro em instalações para mulheres (Hamer, 2019).

No geral, quarenta e cinco por cento do número total de programas de teatro na prisão foram realizados em prisões da Califórnia e quarenta por cento deles estavam no Centro-Oeste. O primeiro dado reflete a longa história de programas artísticos na Califórnia e o segundo demonstra em grande parte a influência 
geográfica e genealógica de Curt Tofteland, do Shakespeare Behind Bars ${ }^{7}$. Além disso, aqui está uma presença significativa de programação na região Centro-Oeste pelo Prison Creative Arts Project (PCAP) ${ }^{8}$ que é afiliado à Universidade de Michigan e dirigido pela Dra. Nora Krinitsky. Os quinze por cento restantes dos praticantes estavam localizados na Costa Leste e no Sul.

A paisagem forte e específica da geografia da prisão se reflete na consciência de Cedric de que sua própria experiência na prisão não pode ser generalizada, e que ele não afirma falar por ninguém além de si mesmo. Ele é rápido em enfatizar que sua experiência na prisão está longe de ser típica. Em particular, Cedric enfatiza o que Karen ouviu ressoar em sua pesquisa: o Department of Corrections $(D O C)^{9}$ de cada estado é diferente de todos os outros estados. Assim, o Departamento de Correções do Colorado (CDOC, sigla em inglês), no qual Cedric está preso há vinte anos, é diferente dos sistemas penais de outros estados. Além disso, cada um dos vinte e dois estados operacionais e prisões privadas do CDOC é diferente dos outros.

Como é o caso em todos os estados dos EUA, a dinâmica das pessoas presas e funcionários, em todas as suas combinações e permutações, variam a cada prisão. Da mesma forma, há variação nas sutilezas do chamado "código de condenação", um conjunto rigoroso de regras pelas quais as pessoas aprisionadas respeitam ou enfrentam represálias de outras aprisionadas. O que é aceitável em um espaço vai fazer prisioneiros feridos ou mortos em outro. Há programas e oportunidades que são possíveis dentro da cultura da Penitenciária Sterling, por exemplo - onde Cedric estava envolvido com o DUPAI - que nunca seria possível na Instalação Correcional de Fremont, onde Cedric estava na aula de teatro de Karen. Em Sterling, Cedric procurou estabelecer o que ele considera uma "arte cabal reabilitadamente orientada" que era composta por prisioneiros e funcionários que compraram a ideia de uma experiência de prisão mais saudável, um empreendimento que não teria sido possível da mesma forma em outro lugar.

\footnotetext{
7 Tradução: Shakespeare Atrás das Grades.

8 Tradução: Projeto de Artes Criativas da Prisão.

9 Tradução: Departamento de Correções.
} 
Assim, as experiências de Cedric são particulares para as prisões em que ele foi encarcerado e para sua própria visão de mundo e métodos de operação nelas. Elas são específicas para ele como um artista e estudioso com suas próprias maneiras de ver. Da mesma forma, as experiências de Karen emergem de sua jornada como praticante de teatro e estudiosa da prisão, mas também vêm de sua posição como diretora artística de uma companhia de teatro sem fins lucrativos, e do papel de mãe de dez filhos. Os autores convidam o leitor a ter isso em mente enquanto compartilham as histórias de suas jornadas, e as jornadas dos outros, pois é em jornadas juntos, e compartilhando nossas histórias (Simpson et al. 2019) que reunimos coragem para abrir um amplo caminho para os outros, crescemos em amor um pelo outro, e nos tornarmos bons, sábios e fortes.

\section{O espaço sagrado do Teatro na Prisão}

No final de 2016, quando Cedric entrou em uma aula voluntária de Teatro em uma prisão no Colorado, ele nunca suspeitou que, como uma criança através de um guarda-roupa encantado, estava entrando em um novo mundo mágico. Além de seus visitantes na sala de visitas, o praticante de Teatro voluntário que o cumprimentou foi a primeira pessoa que olhou para ele e viu um ser humano em vez de um prisioneiro. Cedric descreve seu primeiro encontro com Karen da seguinte maneira:

Esta pequena e linda mulher me recebeu tão calorosamente em sua aula que eu me perguntava se ela não tinha me confundido com outra pessoa. Ela estendeu a mão sem hesitação ou medo e eu fui pego completamente desprevenido. Eu estava esperando ser olhado com apreensão, preparado para me desculpar pela minha intrusão e prometer não voltar. Quando percebi que ela não tinha cometido um erro, uma pequena fenda se abriu na carapaça dura da indiferença que eu tinha formado como armadura contra as duras verdades da vida na prisão. com desprezo e autoconfiança, a voluntária de Teatro reuniu a insegurança, a inexperiência, a dúvida e a reticência que emaranharam nosso pequeno grupo e nos teceram em uma verdadeira trupe de atuação. Ela era uma artista e, nós, seus meios. Estava tão longe da minha experiência anterior na prisão que parecia errado. Baixei lentamente as paredes defensivas e uma versão vulnerável de mim pudesse espreitar a 
cabeça para cima. Assim começou a metamorfose de Cedric Martin.

Vale a pena habitar por um momento no calor desse novo acolhimento e abraço - não um abraço literal, é claro, porque isso é prisão. No entanto, cada vez que um facilitador de Teatro oferece boas-vindas a um novo participante do Teatro no círculo - ou amontoado (Zelon, 2001) - ou o conjunto que está no coração de uma trupe de Teatro na Prisão, algo quase imperceptível muda brevemente o foco: o conhecimento de cada um importa e que cada chegada é digno de comemoração. Assim como existe um código de condenado, existe um código de voluntariado de teatro, e é este: "você é bem-vindo, você é valorizado, você é amado". Com o tempo, existe uma moeda forte de confiança (Armstrong, 2014) que lentamente substitui a "carapaça dura da indiferença". Como prova disso, Cedric descreveu sua experiência na sala de Teatro na Prisão como o primeiro lugar na prisão, além de com seus visitantes na sala de visitas, em que se sentia visto e tratado como um ser humano, capaz finalmente de "[baixar] paredes defensivas" para que uma "versão vulnerável de mim" pudesse "[espreitar] a cabeça para cima".

Há obstáculos na prisão para o vínculo, essa necessidade fundamental de saber que se é humano (Smith, 2010). Apesar de ser o terreno comum para se encontrar com entes queridos do mundo exterior, as salas de visita são espaços disputados (Moran, 2013) com todo o charme de uma sala de espera hospitalar. Na prisão, a intimidade é cercada com grades e às vezes é preciso ter medo de como você toca ou fala com sua família. Você sempre precisa estar alerta e não pode ir para o chão brincar com os bebês. Não pode segurar a mão da sua namorada ou beijá-la. Não pode jogar palavras cruzadas com sua mãe. Não ria alto; não chore. Em vez disso, faça algo falso, tenso e difícil de se conectar.

Assim, os únicos espaços tradicionais que os presos têm para se conectar com seus entes queridos são em ambientes vigiados e estressantes, portanto o espaço do Teatro na Prisão - seja sala de aula ou espaço mágico de performance - assume uma vida própria. Os espaços teatrais tornam-se "espaços livres" nas prisões (Crewe et al., 2014) onde uma pessoa pode ser seu eu autêntico e esquecer 
por um tempo que ele ou ela está na prisão. É também um espaço no qual as pessoas podem começar a pertencer umas às outras (Lucas, 2020). Esses são os espaços nos quais seres humanos cansados podem começar a derrubar a "carapaça dura da indiferença" que construíram contra as formidáveis lutas da vida na prisão.

\section{Bem-vindos ao abraço mútuo}

É um trabalho ousado e delicado, tecer e entrar em espaços livres nas prisões (Crewe et al., 2014). Para Lana, a sensação de acolhimento esperando por ela na sala de aula de Teatro na Prisão foi uma experiência poderosa que ajudou a sustentá-la ao longo de sua viagem de 177 km (ida e volta) da e para prisão do norte, onde ela ministrava uma aula semanal sobre Shakespeare em um local remoto:

Acho que em um nível para mim, como praticante de teatro, que o Teatro realmente faz a diferença na vida das pessoas [isso é significativo], mas se eu puder ficar ainda mais egoísta sobre isso e dolorosamente honesta, parte do que eu ganho com isso é uma sala onde eu tenho 25 irmãos que estão over the moon to see $m e^{10}$... Agora, eu não comecei a fazer trabalho na prisão porque eu sabia como seria - quero dizer, você tem que descobrir isso - então, em algum nível subconsciente ou outra coisa me levou lá. Mas agora que estou nisso, sei que uma das coisas que recebo é um tipo de amor fraternal que não estava disponível na minha família de origem... então, eu não sei o tecido conjuntivo ou o fio, mas eu sei que isso é um pedaço de mim. (Lana, voluntária de Teatro).

Essa sensação de acolhimento e abraço no espaço do Teatro na Prisão foi livremente nomeada e reconhecida pelos voluntários de Teatro. Era um espaço de liberdade para eles: liberdade para se sentirem sem julgamentos; liberdade para entrar em um amplo círculo caloroso de boas-vindas no final de seu dia; liberdade para falar abertamente e honestamente e possuir tempo para isso. Não havia celulares nem distrações. Devido à natureza voluntária dos programas de Teatro na Prisão, muitos dos quais não rendem "redução da pena" a ninguém, as pessoas estavam lá porque queriam estar, tanto participantes encarcerados quanto voluntários. Apenas 8\% dos voluntários do Teatro na Prisão nos EUA consideram

10 Tradução: Sobre a lua para me ver 
isso seu trabalho de "tempo integral". Todos os outros fazem isso por amor e alguns para ganhar um pouco de dinheiro. Em resposta, os participantes encarcerados muitas vezes se sentem profundamente gratos, e frequentemente alertam os voluntários de que você não precisa estar aqui, mas estamos tão felizes que você está.

No entanto, há um senso de que os voluntários sentem que "têm que estar lá". Não é um fardo de obrigação, mas um compromisso que é mais frequentemente descrito como repleto de alegria. Como Lana apontou acima, ela "não entrou no trabalho na prisão" porque sabia que receberia as boas-vindas. Mas ela foi atraída pelo trabalho porque o acolhimento é abrangente, edificante e forte. Para outros voluntários que são professores de primeiro grau ou professores universitários, eles encontram descanso e alívio nos principais grupos de Teatro na Prisão após uma semana de disputas com estudantes cuja atenção é diferente daquela construída pelo espírito cooperativo que muitas vezes caracteriza uma sala de aula de teatro prisional. Eles também reconhecem rapidamente que não teriam "nenhum interesse" em executar programas de teatro em que não fossem voluntários. Eles têm certeza de que uma das alegrias e sucessos da criação de uma comunidade de apoio do Teatro na Prisão é que as pessoas estão lá porque escolhem estar - cada uma delas.

No entanto, pode haver uma desvantagem para esta recepção feroz e liberal. Cedric está ciente de que atrai a ira daqueles que acham que programas de Teatro na Prisão devem ser exclusivos para detentos bem comportados. Observa que eles ressentem seu envolvimento e a persistência dos voluntários em incluí-los. No entanto, os voluntários carregam uma certa quantidade de capital social e pessoal em um espaço onde eles não são funcionários da unidade (Tomczak \& Albertson, 2016) e de onde eles vêm do mundo livre, como uma espécie de ar fresco em um espaço obsoleto e monótono.

\section{Vulnerabilidade: vulnerabilidade como força}

Desde 2018, Cedric tem tido a sorte e o prazer de trabalhar com duas 
voluntárias do teatro, Dra Ashley Hamilton e Julie Rada, em uma nova empreitada pelo CDOC. Em um experimento inovador, ele foi capaz de abrir o caminho para a Dra Hamilton trazer a luz do DUPAI para iluminar a barriga escura da Unidade de Controle de Gestão ( $\left.M C C^{1}\right)$ mais segura do Departamento de Correções do Colorado ( $C D O C)$. Quatro dos prisioneiros mais perigosos do Colorado, infelizmente ele sendo um deles, foram escolhidos para participar. O que se seguiu foi pura magia. Homens que acreditavam que exibir, admitir ou falar sobre emoções era um sinal de fraqueza logo viriam a mostrar uma verdade radicalmente diferente. Cedric testemunhou aqueles homens amadurecerem, no curto espaço de tempo que a aula foi autorizada, a um grau que ele achava notável.

Transformador, curativo, reabilitador... Cedric usa essas palavras cuidadosamente por causa de sua própria experiência de buscar ativamente ajuda - "vocalmente, vociferantemente, incessantemente" - durante suas estadias na solitária, sem sucesso. Há muitos prisioneiros que afirmam que não foram psicologicamente prejudicados pela solitária. Uma interação de cinco minutos com eles prova o contrário. No entanto, o CDOC usará o machismo equivocado dessas pessoas para defender o uso dessa tortura devastadora na qual Cedric vê os homens endurecidos ao ponto de uma fragilidade quebradiça e rígida. Ele os vê ficar assim até que se quebrem.

Um benefício periférico é que muitos dos companheiros de Cedric, alguns dos quais são extremamente misóginos, tiveram suas percepções sobre as mulheres dramaticamente alteradas por causa de seus encontros neste espaço teatral. Se não fosse pela programação teatral e artística criativa no MCC liderada pela Dra Hamilton, esses homens nunca saberiam que a vulnerabilidade poderia ser equivalente a força. Por meio da presença e do processo de voluntários atentos, articulados e atenciosos, esses homens começaram a se sentir confortáveis em se abrirem. Eles então começaram a olhar para partes de si mesmos que estavam sem cuidados desde sua ferida originária - um processo que Bessel van der Kolk (2014) descreve como essencial para chegar a um acordo

\footnotetext{
${ }^{11}$ Sigla em inglês para Management Control Unit.
} 
e, eventualmente, transformar traumas e dores passados.

\section{Vulnerabilidade, insinuações e medo}

As voluntárias não desconhecem sua vulnerabilidade. Uma voluntária na casa dos vinte e poucos anos, Natalie, entrou atrasada na prisão um dia para seu programa, e ela estava atravessando o quintal sozinha, o que a levou a ter que andar:

...em um tempo que eu nunca tive antes onde todos estavam fora... Não vi um único oficial... Eu não estava com medo, mas eu estava desconfortável... Estavam assobiando pra mim... Estavam assobiando pra mim - Eu senti uma estranha mistura de culpa por não fazer contato visual com aqueles humanos, mas também uma estranha mistura de medo porque eu sou vulnerável... Eu estou procurando desesperadamente por um dos caras que está no nosso grupo e eu vejo alguém e ele está muito à frente e foi como, foi a sensação mais estranha, foi a sensação mais esperançosa como - Eu preciso que você me veja e mesmo se você não me ver, se eu chamar o seu nome caso algo aconteça, você vai me ajudar ... Ninguém mais poderia entender isso, exceto alguém que entra, outra fêmea que entra (Natalie, voluntária de teatro).

Natalie estava profundamente ciente do espaço vulnerável que existia fora do espaço do teatro na prisão, no qual ela não era recebida com alta consideração. Esse foi um forte contraste com sua experiência dentro do espaço do teatro, no qual a regra não escrita é profunda, de profundo respeito pelas voluntárias que se debruçam beirando à reverência. É um espaço onde avanços sexuais, insinuações e comportamento rude ou grosseiro de prisioneiros do sexo masculino em relação a voluntárias femininas estão fora dos limites. Embora Cedric reconheça que a maioria das voluntárias que conheceu são mulheres atraentes - não é surpresa, dado que a maioria da programação teatral nas prisões masculinas é dirigida por voluntárias mulheres -, ele afirma que seu verdadeiro valor está em suas mentes e corações e insiste em que as mulheres sejam tratadas de uma forma que reflita tanto a raridade quanto a preciosidade de sua presença. Este espaço protegido, no qual as voluntárias reconhecem que se sentem seguras e respeitadas, às vezes contrasta com a vulnerabilidade que podem sentir no pátio. 
Há uma posição contrastante para este tratamento rarefeito de voluntárias femininas no teatro na prisão, no entanto. Por parte de Natalie, ela muitas vezes deseja poder contornar a natureza de gênero da prisão, a fim de "ser apenas outra pessoa em um grupo de amigos trabalhando em uma peça" mesmo reconhecendo que não é tão simples. Ela é rápida em acrescentar que, ao contrário de sua experiência no pátio, ela "nunca se sentiu desrespeitada por um único indivíduo no grupo [do teatro]".

\section{Vulnerabilidade e transformação da dor}

Para voluntários que carregam conflitos e feridas que são percebidos de perto dentro do sistema prisional, é profundamente corajoso entrar no mundo do teatro na prisão. Muitas vezes, eles levam alguns meses, ou mesmo anos, para lentamente entrar no espaço como um único ou principal facilitador de teatro. Acompanhar um voluntário veterano ou mais experiente pode ser um caminho inicial para o papel de facilitador do grupo.

Há um poderoso fluxo bidirecional de cura que funciona para prisioneiros e voluntários no espaço relacional e artístico do teatro na prisão. Essa realidade repercutiu com um praticante de teatro voluntário cuja jornada para a facilitação do teatro na prisão foi lenta e fortemente repleta de emoção em torno do estupro de um amigo próximo em anos anteriores.

Eu me refiro a ela como aquela área cinzenta que eu não queria que existisse na minha vida, eu queria ter "você é bom" ou "você é mau e as pessoas que fazem isso devem ir para a cadeia". Mas, então, [ver] todos esses caras e ver a beleza e a verdade e a humanidade nessas performances e conhecer alguns deles... para mim foi um enorme crescimento na forma como eu pensava sobre as pessoas na prisão. E eu acho que há um elemento de mim tentando consertar o que aconteceu fazendo este trabalho. (voluntário do teatro).

A vontade desse voluntário de abraçar sua própria ruptura, e encontrar a totalidade além dela, é prova da força, da vulnerabilidade e do abraço mútuo dos participantes do espaço do teatro na prisão, participantes encarcerados e 
voluntários. No movimento lento de um em direção ao outro, é possível se sentir fora do espaço seguro e testar, a fim de descobrir o que será possível, como Cedric observou anteriormente, para uma "versão vulnerável de mim" erguer a cabeça. Mais uma vez, vemos que o espaço do teatro na prisão pode ser uma arena de cura mútua, quando as pessoas estão presentes umas para as outras, com respeito mútuo, vulnerabilidade e tempo. Torna-se intrigante considerar se é realmente possível responder à pergunta gentil da criminóloga Alison Liebling (2012), os humanos podem florescer na prisão? com a resposta qualificada do teatro improvisado de um curioso "Sim - e -?"

\section{Treinamento voluntário e (des)confiança}

Se os voluntários do Teatro na Prisão recebem ou não qualquer forma de pagamento por seu trabalho - sendo que a maioria não - todos são classificados como voluntários pelas leis estaduais, a menos que gerenciem um grupo de Teatro como funcionários de uma prisão. Na época da pesquisa de Karen, em 2018, ela conhecia apenas uma pessoa que dirigia um grupo de Teatro na condição de funcionária da prisão. Além disso, os autores conhecem apenas duas trupes de Teatro que foram iniciadas por participantes encarcerados: The Phoenix Players Theatre Group ${ }^{12}$ no Auburn Correctional Facility ${ }^{13}$ em Nova York e The Sisters Within Theater Troupe ${ }^{14}$ no Florence Crane Correctional Facility ${ }^{15}$ em Coldwater, Michigan. Os autores estariam interessados em ouvir sobre outros grupos que criaram um espaço para si mesmos no ambiente carcerário.

Além dos facilitadores dos grupos acima mencionados, os voluntários normalmente precisam passar por um treinamento voluntário obrigatório pelo Estado. Isso é considerado pela maioria dos voluntários como "irrelevante" ou

\footnotetext{
12 Tradução: Grupo de Teatro Os Atuantes de Phoenix

13 Tradução: Centro de Correcional de Auburn

14 Tradução: Trupe de Teatro As Irmãs Encarceradas

15 Tradução: Centro Correcional Florence Crane
} 
"principalmente irrelevante" e foi resumido com ironia pelo voluntário veterano, Charles, como: "Não faça sexo com os presos".

\section{Primeiras aulas em (des)confiança na prisão}

A maioria dos voluntários penais nos EUA são voluntários religiosos, e não artistas ou outros (Abrams et al., 2016). Isso se reflete nas referências de voluntariado, a maioria das quais consiste em pesquisas sobre voluntários religiosos (por exemplo: Tewksbury \& Dabney, 2004; Tewksbury \& Collins, 2005). Kathy, uma voluntária de Teatro na Prisão que atuou em várias prisões em dois dos estados do sul dos EUA em que ela descreveu como sendo "muito conservadores, estados muito antigos administrados por um clube de homens" e ficou particularmente angustiada durante o evento de treinamento dos voluntários que ela participou, no qual "meu sentimento era de que todos naquela sala eram voluntários baseados na fé, exceto [meu colega praticante de Teatro] e eu". Ela continua dizendo que estava "impressionada com a intensa inclinação [religiosa] deste treinamento voluntário em uma instalação do estado".

Embora Kort-Butler e Malone (2015) contem histórias de voluntários religiosos carinhosos e altruístas que enxergam seu papel como construtor de relações com os indivíduos encarcerados, os voluntários tiveram o cuidado de distinguir essas relações de amizades. Em seu estudo, a amizade foi definida como tendo uma qualidade de troca que foi considerada pelos voluntários religiosos como inadequada em um ambiente prisional. Essa ausência de consideração do importante papel da mutualidade em um ambiente prisional é rigorosamente identificada por Cedric, que observou que "alguns, embora não todos" dos voluntários religiosos que ele encontrou parecem "andar por aí expondo todas as coisas que estamos fazendo errado". Isso contrasta com os voluntários do Teatro na Prisão, a quem ele considera, mais favoravelmente, por estarem dispostos a fazerem um convite para uma relação significativa no ambiente carcerário, em vez de levantar obstáculos em um lugar tão repleto de barreiras, aos quais determinam até para onde você andará: entre as linhas amarelas, para os 
voluntários e funcionários; pelo lado de fora, para os menores e condenados.

Os processos suspeitos das prisões: confiança, guardas e voluntários

Os voluntários do Teatro na Prisão estão conscientes de que são admitidos na prisão apenas a convite da administração - ou, mais provavelmente, em determinado dia, ao prazer do policial na recepção. Relata Emma,

Um policial me disse uma vez, literalmente, quando eu estava tentando trazer um fichário de três anéis [para a aula]... "Não quero ser esfaqueado pelas costas com isso". E eu disse, "É um fichário de três argolas, tipo, isso realmente pode acontecer?". "Sim". E então, algumas das regras que eu também acho meio ridículas, é como se eles imaginassem que todas as coisas possiveis poderiam ser usadas como uma arma, que poderiam ser usadas para uma fuga, tivemos problemas em trazer até narizes de palhaço.

Em certo sentido, uma vez que os voluntários do Teatro na Prisão entram no portão de entrada de uma prisão, eles estão sujeitos aos regulamentos e procedimentos da mesma, em risco de serem transformados em um "objeto de informação [em vez de] um sujeito em comunicação" (Foucault, 1977, p. 200). Como os prisioneiros - embora claramente com diferenças legais, de direitos e poder - os voluntários não têm liberdade para propor tudo o que desejam fazer em sua prática teatral, como fariam fora dos portões da prisão em um ambiente comunitário. Como Emma descreve acima, os voluntários estão sujeitos aos caprichos dos funcionários da prisão.

Muitas dessas exigências se estabelecem em torno da segurança e das reivindicações de segurança, como no caso de Emma com "problemas em trazer narizes de palhaço" que podem ser usados para disfarces de fuga. Isso contrasta hilariamente com os disfarces reais que Tanya inadvertidamente pediu quando ela foi uma voluntária de Teatro recém-chegada:

Eu era tão ingênuo no começo. [O pessoal da prisão] disse: "Oh, vamos 
fazer uma lista do que você está trazendo [para dentro]", então eu falei tipo "garrafa de álcool, paraquedas, máscaras"” e eles falaram que todos os materiais eram de fuga - e eu fiquei tipo, "Oh, merda!". Então, quando voltei eu basicamente mudei as palavras, mas continuava sendo as mesmas coisas: grande pedaço de material, tintas faciais para máscaras. Então, no final, eles concordaram.

O Teatro é um desafio no cenário de segurança da prisão, onde um salto sobre uma cadeira durante um ensaio para The Tempest ${ }^{16}$ pode provocar uma explosão de fúria de um dos guardas, como aconteceu um dia na sala de aula do voluntário Travis: "O que diabos está acontecendo aqui?", exigiu o guarda. "O que aquele cara está fazendo em pé em uma cadeira?"

Pode não ser uma explosão de fúria de um guarda, correndo para a sala de ensaio em direção ao ator ofendendo-o por estar de pé na cadeira; pode ser um suspiro alto de um supervisor na parte de trás da biblioteca quando um artista faz passos não ensaiados em uma pequena mesa de café durante uma tarde tranquila em uma apresentação de monólogos shakespearianos. Isso provavelmente será seguido por uma visita do supervisor quando o diretor interroga o elenco após a apresentação, juntamente com uma advertência severa de "Nunca mais faça isso".

\section{Táticas de navegação: entrar e aprender à medida que avança}

O valor de ter um advogado como administrador da prisão, ou como um dos supervisores, não pode ser exagerado, tanto por entrar na prisão para executar um programa de teatro, quanto por ajudar a navegar em obstáculos à medida que eles surgem. O sucesso da Iniciativa Denver University Performing Arts ${ }^{17} \mathrm{com}$ o CDOC ilustra o potencial em obter um programa dentro dos muros da prisão quando a universidade tem uma parceria do mais alto nível com o Departamento de Correções do estado, o último "guardião das chaves". (Tofteland, 2011).

Se você é professor em uma universidade, você pode descobrir, como vários

\footnotetext{
${ }^{16}$ Tradução: A Tempestade

${ }^{17}$ Tradução: Iniciativa de Artes Cênicas da Universidade de Denver.
} 
voluntários no estudo de Karen descobriram, que você tem sorte quando chega a uma prisão para saber sobre o lançamento de um programa de teatro na prisão. Kevin é um desses professores em uma universidade do centro-oeste, que começou com tanto mistério à sua frente como qualquer outro voluntário quando ele estava procurando um caminho de entrar como voluntário na prisão:

Há um site para entrar [na prisão] como facilitador, então eu fui lá e procurei os nomes e dei um palpite de com quem eu preciso entrar em contato. E, essencialmente, eu escolhi três nomes da página, e disse "estes soam como o tipo de pessoa com quem eu preciso falar", então eu enviei um e-mail para aqueles três e esperei resposta. Eu realmente não sabia o que a entrada significava, então eu não escolhi essa. Eu acho que havia algo que era para ser diretor de comunicações, talvez - e havia outro para diretor de programas e eu pensei, ok, tem que ser um deles. Então eu pensei que se eu enviasse para algumas pessoas, se eu não acertasse o certo eu acertaria alguém que estaria interessado.

Mesmo que Kevin fosse um professor da área de Humanas, e adepto de localizar e interpretar textos, ele experimentou um nível surpreendente de mistério em relação a quem ele alcançaria naquela prisão local, quando ele estava pensando em começar um programa de teatro por lá. O caminho não estava sinalizado ou aberto. Contudo, Kevin rapidamente fez contato e recebeu resposta da pessoa que se tornaria seu apoiador durante os cinco anos de seu voluntariado, mas este não é necessariamente o caso de um voluntário individual que não é afiliado a uma universidade ou uma organização bem conhecida.

A experiência de Lana contrastou com a de Kevin, como ela comentou: "Quero dizer, é um mistério, certo, como você entra? E, claro, as unidades prisionais são tão secretas de certas maneiras, que é realmente difícil descobrir quem é a pessoa com quem você está em contato, com quem devo falar?" A experiência de Lana é semelhante a de outros indivíduos que procuraram uma maneira de entrar na prisão, tentando chegar aos diretores por e-mail, às vezes por meses a fio, tentando descobrir quantas vezes pode ser considerada muito frequente, para então enviar uma nova mensagem. Os muros da prisão, ao que parece, podem ser tão opacos e impenetráveis por fora quanto por dentro.

Aprender o jargão, os protocolos, até mesmo a localização das prisões pode 
ser um desafio. Por um lado, as prisões não estão necessariamente em mapas. Toda a novidade em torno de descobrir o que significa elaborar um programa em uma prisão - essencialmente, como se alinhar às necessidades da instituição e aos procedimentos burocráticos opacos - foi descrita por Tanya desta forma:

Foi um pesadelo. Então, basicamente, no começo eu tive essa ideia e fui para [meu chefe, que me disse] ir fazer isso, por parecer incrível. Então eu pesquisei prisões na Califórnia - sem pista, eu estava chegando- "Oh, [nome da prisão], isso soa muito bonito." Eu nem olhei para um mapa, eu só liguei para eles e disse: "Vocês estariam interessados em uma oficina?" e eles disseram, "Sim, você pode vir hoje? Ninguém nunca vem aqui". E eu pensei "incrível" e eu olhei em um mapa, "Catorze horas, não, eu não posso fazer isso" - porque naquela época o programa que eu tinha imaginado era semanal e você não pode dirigir catorze horas em cada sentido uma vez por semana.

Tanya aprendeu rapidamente o que todos os voluntários experientes eventualmente aprendem: a prisão faz as coisas em seus próprios termos. Se os administradores da prisão querem o que você oferece - seja a programação para uma prisão sem recursos ou status de conexão com uma universidade - as portas se abrirão tão rapidamente e tão amplamente que você pode se sentir tão surpreso quanto Curt Tofteland (2011, p. 1215): "Se [o] começo soa como um acaso, então foi. Eu caí na oportunidade".

\section{Navegando pelo desconhecido: venha o inferno ou enchente}

Não só a prisão faz o que quer - ou, pelo menos, é assim que os prisioneiros e os voluntários se sentem - como se comunica como quer. Assim, voluntários como Kevin podem ficar no limbo por semanas, sem saber às vésperas de uma estreia se o ator principal estará disponível devido a um confinamento em toda a instalação. É certo que uma mudança extrema geralmente é uma resposta a um evento extremo, como um assassinato na prisão; no entanto, interrupções diárias podem ocorrer sem comunicação aos voluntários, mesmo em acontecimentos menores.

Raramente mecanismos simples existem no local para comunicar bloqueios 
aos voluntários, que podem dirigir até dez minutos para chegar às instalações do programa de teatro na prisão, ou até três horas, uma ou duas vezes por semana. Kevin tinha o seguinte a dizer sobre métodos de comunicação prisional, interligando com sua própria tenacidade e determinação para chegar à prisão, para cumprir seu compromisso com seu grupo de teatro:

Às vezes eu me dei bem e é como se o inferno ou enchentes não fossem me impedir de fazer o que eu vou fazer. Eu entrei na interestadual uma vez [e] não foi oficialmente uma nevasca, mas poderia muito bem ter sido - pessoas estavam caindo da interestadual - nenhum acidente fatal ou qualquer coisa do tipo, mas eu estava simplesmente preso no trânsito, apenas preso. Eu nem cheguei à prisão naquele dia... Ocasionalmente, e isso aconteceu nos últimos dois meses e meio, eu dirijo todo o caminho até lá e eles dizem, você sabe que tivemos um confinamento aqui hoje às dez horas... Ocasionalmente eles se lembram de ligar para o meu número de celular ou algo assim, mas isso é em parte devido a quem está de plantão naquele dia e o que essa pessoa pensa fazer.

Essa é a tenacidade e determinação dos voluntários do teatro na prisão de aparecerem quando dizem que vão - como diz Kevin, venha "o inferno ou a enchente". Esse comprometimento é importante para os voluntários, que estão cientes de que para muitos dos homens e das mulheres aprisionadas que participam do teatro na prisão podem ter sido - ou foram -, desapontadas por causa de uma série de compromissos quebrados ao longo de suas vidas. Voluntários querem ser confiáveis; eles não querem simplesmente dizer que se importam (e eles dizem isso); eles estão profundamente comprometidos em mostrar que se importam.

E é neste estado de cuidado encarnado, como Kevin demonstra dirigindo em de uma nevasca, que os voluntários do teatro tentam absorver um pouco da tensão da prisão em si mesmos, mesmo com certo custo para si. O valor desta demonstração de cuidado permanece, mesmo quando Kevin reconhece que alguns simples procedimentos de notificação por parte da prisão o ajudariam a não realizar viagens desnecessárias, no caso de confinamentos, por exemplo.

Há exemplos mais extremos do custo do cuidado por parte dos voluntários do teatro na prisão do que dirigir pela neve, embora o clima seja um exemplo mais 
consistente, e possivelmente mais fisicamente precário. Às vezes, o ato de cuidar tem um alto custo emocional. Foi o caso de Chad, um voluntário experiente que havia negociado um encontro com o público no final da apresentação noturna de seu programa de teatro, sujeito à disposição dos artistas de se submeter a uma vistoria no fim da apresentação da noite. Chad tinha discutido este tópico com o elenco, que, no passado, tinha sido capaz de se misturar livremente com o público após uma apresentação. No entanto, tendo concordado com as regras de uma nova administração prisional, Chad ficou atordoado quando descobriu, na noite da apresentação programada, que a permissão para aperto de mão havia sido retirada, aparentemente no último minuto.

Todos concordaram com uma vistoria completa para poder apertar as mãos dos membros da plateia - [tinha sido acordado e então] eles me disseram, não, não haverá nenhum contato físico. Então é só isso, sabendo que então eu tenho que entrar e ter essa conversa com o grupo porque eu não quero que o responsável faça isso porque ele vai dizer isso de uma forma muito rude.

Ele não só estava atordoado, ele estava furioso, uma fúria justa com a injustiça e a humilhação que os homens do elenco estavam sofrendo - não só porque eles tinham concordado que seus corpos seriam despojados e inspecionados pelo privilégio de apertar as mãos de seus entes queridos naquela noite, mas porque este acordo degradante tinha sido ainda mais degradado por uma negação de reviravolta. Em vez de permitir que o responsável pelo programa comunicasse essa mudança de última hora aos homens na noite da apresentação - porque ele sentia que ele se comunicaria de uma forma que humilharia os homens - Chad optou por fazer o pronunciamento ele mesmo, carregando o custo do amor em seu próprio corpo e emoções.

Esse amor cansado podia ser ouvido em sua voz enquanto falava com Karen sobre o processo de ter que ir regularmente falar com os superiores para tentar corrigir os erros e criar um espaço mais humano para as pessoas fazerem teatro nas prisões, particularmente no difícil e volátil cenário de prisões juvenis. "Eu não posso dizer para você ir se ferrar, eu não posso" ele riu, um pouco sombrio, 
enquanto ele explicava a contínua falta de compreensão e apoio dos funcionários para os jovens em seu programa, a ponto de eventualmente contratar outro voluntário para assumir o trabalho juvenil. Essa decisão surgiu no ponto em que o custo parecia muito alto para pagar. Assim como "cair" na prisão para voluntários pode ser uma reminiscência da descrição de Annie Dillard (2013) de escrever um livro como "a sensação de girar, cega pelo amor e ousadia" ,assim é "cair" da mesma forma vertiginosa, sobrecarregada de cansaço e tristeza, mas com olhos muitas vezes ainda cegos pelo amor.

\section{Mutualidade}

Quando Karen entrou em uma prisão masculina no Colorado, em 2015, como voluntária para dirigir uma aula de teatro, mal sabia ela que havia algo como o "teatro na prisão". Até onde Karen sabia, ela estava simplesmente fazendo uma aula de teatro. Na verdade, um de seus objetivos era realizar ensaios na prisão da mesma forma que ela fazia na comunidade fora da prisão: em um espírito de colaboração e mutualidade. Isso foi importante instintivamente. Embora Karen tenha se formado em Educação, a abordagem que ela adotou para estudar em casa com seus próprios filhos foi de um aprendizado natural. Ela acreditava que em um ambiente de apoio que enfatizasse a curiosidade, a colaboração e a experimentação, as pessoas poderiam ser livres para tentar e falhar. Esta era sua prática como diretora na sala de ensaios de teatro comunitário.

\section{Educação conectada ao participante}

Embora nunca tivesse ouvido o termo, Karen estava demonstrando uma "mentalidade de crescimento" (Dweck, 2006). Quando praticou essa abordagem de aprendizagem e teatro na prisão, que permitia a experimentação e o risco e a prática do fracasso, ela tinha lido o suficiente de Vigiar e Punir, de Foucault (1977) em uma mão e da Pedagogia do Oprimido, de Paulo Freire (1970) na outra, para conhecer - pelo menos intelectualmente - a dinâmica de poder da coerção que 
operava em um ambiente prisional. Ela estava ciente de que uma abordagem centrada na pessoa e de confiança para a colaboração criativa não era como funcionava a prisão. O que ela desconhecia era o grau do impacto que essa abordagem da mutualidade teria sobre as pessoas na sala de ensaio na prisão, incluindo ela mesma.

\section{Mutualidade no teatro na prisão: honra e relacionamento}

O desejo de honrar as pessoas com quem trabalham é um forte compromisso entre os voluntários do teatro. Diz Maureen,

Teatro é sobre relacionamentos. Você não pode atuar junto como dois personagens no palco se você tem um relacionamento ruim... Eu faço amigos facilmente, e eu realmente gosto de estar com os rapazes [na minha aula de teatro]. Isso pode soar estranho, eu sinto que posso ser eu mesma com eles, eu posso realmente ser a pessoa real que eu sou, eu não tenho que colocar uma fachada ou uma máscara. (Maureen, voluntária de teatro).

Assim, Maureen se situa entre aquelas que precisam ser parte do relacionamento, e não aqueles que, como os voluntários religiosos, vêm para estabelecer um tipo de relacionamento como se fosse possível apenas uma troca unilateral. Em vez disso, o "dar e receber" mútuo não é apenas a base da conexão humana significativa como amizade ou coletividade no teatro, é também uma demonstração do teatro como chamada e resposta (Cohen-Cruz, 2010), a personificação do grito vulnerável de Natalie que "eu preciso que você me veja e mesmo se você não me enxergar, se eu chamar seu nome se algo acontecer, você vai me ajudar". Este é o chamado de cada um de nós como seres humanos, o chamado para ser visto; é o grito, do berço ao túmulo, pelo cuidado e segurança buscados a partir da posição vulnerável de precisar saber que "se eu chamar o seu nome ... você vai me ajudar" e não me machucar. É um sinal de que pertencemos um ao outro. 


\title{
Mutualidade no teatro na prisão: conectado e responsivo
}

O desejo de estar conectada e responsiva se reflete nos comentários de Tracey sobre ser real na sala de aula de teatro na prisão feminina, onde ela dirige um programa de teatro:

\begin{abstract}
Eu não vou dar a elas o meu endereço ou algo assim, mas eu vou ser honesta sobre coisas pessoais na minha vida e eu sinto muito, mas eu vou abraçar as pessoas - se alguém está tendo um momento muito difícil, alguém teve uma perda. Então, se for para uma política absolutamente sem toque será difícil para mim porque eu definitivamente tenho que colocar minha mão no ombro de uma mulher ou se elas quiserem me abraçar.
\end{abstract}

A mão no ombro; um abraço; o toque de uma mão... estes são os sinais vivos e respiratórios de que estamos vivos e conectados um ao outro. Fundamental para o teatro, e anátema nas prisões, o toque é uma das concessões de fronteira que os voluntários fazem à barriga faminta da cultura prisional. Embora Tracey reconheça os limites do toque físico nas prisões, os quais os voluntários comentam que são claramente estabelecidos e restritos - embora um pouco esporadicamente, realizados, Tracey também reconhece os limites de suas concessões: "Sinto muito, mas vou abraçar as pessoas" diante da luta e da perda.

\section{Ser 'nós': mutualidade e reabilitação}

A resposta de Tracey lembra as estratégias de "altruísmo subversivo" empregadas por mentores voluntários no estudo de Ruth Armstrong (2014, p. 304) sobre os resultados egressos do sistema, nos quais "a doação de... confiança e aceitação... não era sobre ajudar "eles", mas sobre ser "nós".

Para Cedric, é impossível dizer o que faz da arte em geral, e do teatro em particular, uma ferramenta terapêutica tão eficaz nas prisões. Mas é algo sobre "ser 'nós'". Sua experiência com o mundo do teatro, e com o que ele chama de "os magníficos entregadores desta inesperada panaceia", tem fomentado o 
crescimento, a maturação e a consciência dele como nenhuma outra coisa da qual ele já participou. Considerando que uma vez ele pensou que lutar era justificado, ele agora considera isso "triste, embora necessário".

Embora ambos os autores hesitem em conceder o título de "reabilitação" ao teatro na prisão - que é um título muito complexo e um tema muito difícil para ser abordado aqui - eles reconhecem que há efeitos de reabilitação no teatro para todos os participantes, incluindo os voluntários. Por exemplo, os estudos sobre artes prisionais apontam para ganhos na autoestima dos participantes (por exemplo, van Maanen, 2010) e aumento da confiança ao se envolver com as artes nas prisões (por exemplo, Brewster, 2014). Contudo, Cedric aponta para um mecanismo mais pessoal de mudança em sua vida. Ele coloca desta forma:

O efeito da conexão entre [voluntários] e eu em mimé profundo... Estou muito mais aberto e me envolvendo com meus familiares; com a equipe, eu posso interagir muito mais efetivamente; os outros prisioneiros ao meu redor estão perplexos com a mudança em mim, mas em grande parte tímidos de se juntar a mim.

Esta não é a "reabilitação" que é imposta de fora, por um programa de princípios baseados no risco de tratamento eficaz, desenvolvido por psicólogos canadenses e implantado em todas as prisões do mundo ocidental para fazer a diferença (Cullen, 2005). Este é um movimento de dentro, uma jornada para a relação consigo mesmo através de ser abraçado em uma conexão com os outros. Isso é intimidade, e está no centro da dinâmica relacional na aula de teatro entre voluntários e participantes encarcerados e dentro da equipe teatral. Esse pertencimento relacional é o "elo perdido" em pesquisas de reabilitação, bem como em pesquisas sobre voluntários nas prisões (Tomczak \& Albertson, 2016) e pesquisas sobre artes em prisões de forma mais ampla (veja Simpson et al. 2019).

\section{A intimidade da mutualidade}

Quase um ano depois do primeiro convite por e-mail da bibliotecária da 
prisão em Cañon City, Karen participou de uma conferência da Shakespeare in Prisons Network na Universidade de Notre Dame, Indiana. Como parte de um extraordinário e inspirador grupo de pessoas que praticavam teatro nas prisões, Karen conheceu Eddy. Eddy havia participado de um júri no início do dia, durante o qual ele havia falado sobre algumas de suas experiências com o teatro enquanto esteve preso. Karen se aproximou para falar com ele mais tarde naquela noite, depois do jantar.

Eddy falou calmamente, tão silenciosamente, que Karen teve que descobrir como se inclinar para ele sem parecer intrusiva ou como se tivesse uma ligadura nervosa espinhal. E ele falou lentamente, então havia grandes lacunas entre palavras, entre frases. Karen tentou falar calmamente, lentamente, gentilmente, também. Ela não queria assustá-lo. Ela sabia que era capaz de se afobar e se atropelar, e assim ela tentou acalmar sua curiosidade, sentindo que ela estava prestes a reunir um tesouro precioso, cortado de rocha frágil que poderia se fragmentar se ela pressionasse muito forte, muito rápido.

Mas o que fez a diferença naquela sala de aula de teatro para você, Eddy? o que o tornou diferente de outras classes ou outros espaços na prisão? Foi isso... [agarrando para tentar nomear o conceito em troca de seu silêncio]...Foi amizade?

Eddy: Não, não é amizade. [muitas lacunas] Eu tinha amigos, eu sabia o que era amizade. Era mais do que amizade: era intimidade.

Karen: O que quer dizer com isso, por intimidade?

Eddy: Quero dizer que os voluntários estavam dispostos a se abrir para nós, estavam dispostos a dizer estou tendo um problema com isso ou com isso. Não era apenas uma maneira - [lacuna; mudança de peso e inclinação em mais]: intimidade.

Isso foi tudo o que Karen colheu de Eddy, mas ele firmou com um nome a energia relacional dinâmica da sala de aula do teatro da prisão que fez dele um precioso, rarefeito, carregado, transcendente, e, sim, espaço íntimo. Karen ouviu essa descrição, se não o termo exato, repetida nas palavras de voluntários do teatro na prisão em todo o país e em todo o mundo, enquanto descreviam o impulso primário e a necessidade humana de ver e ser visto, conhecer e ser 
conhecido, importar e ser importante. Isto é o que Cedric reconheceu e encapsulou quando disse que era "o efeito da conexão... comigo em mim" que foi tão profundo para ele. Ele, também, quis dizer: intimidade.

Intimidade: transparência como amor na sala de aula do teatro na prisão

O que eu não estava preparado era para me apaixonar... Com isso quero dizer, eu não estava preparado para a intensidade do ambiente prisional, a alegria das discussões que tivemos sobre a peça, o profundo amor e respeito que desenvolvi pelos homens com quem trabalhei, ou a riqueza da rede de pessoas que eu conheci que também estavam fazendo esse trabalho. (Karen)

Possivelmente, parte do poder do teatro na prisão decorre da transparência dos voluntários. Isso contrasta com o que Cedric descreve como a abordagem que ele experimenta dos funcionários prisionais, na qual os agentes querem que os prisioneiros - querem que ele - se sintam punidos e existam em um estado constante de miséria. Ele trabalha para evitar isso. No entanto, aqueles ao seu redor, tanto os agentes quanto os outros prisioneiros, parecem endossar a crença de que as pessoas encarceradas são intrinsecamente defeituosas. "Mal", "incorrigível", "corrompido": são palavras que eles ouvem com frequência. Foi tomada uma decisão de que qualquer coisa que dê prazer aos prisioneiros irá necessariamente alimentar seus corações malignos, distorcidos e demoníacos - e, portanto, deve ser negada. Em contraste com essa afirmação do "mal encarnado", Cedric está ciente de que os voluntários até se preocupam com como ele se sente; ele está ciente de que a ideia de sua felicidade os faz felizes. Essa poderosa alquimia muda a forma como ele experimenta seu ambiente.

Em vez de suspeitar, voluntários do teatro trabalham de um lugar de confiança. Em vez de exílio, eles trazem intimidade, embora uma intimidade limitada, com presença e conversa através da mutualidade, vulnerabilidade e transparência que cria uma intimidade que o artista de teatro Travis chama de "cor" que "ajuda [as pessoas] a lembrar as nuances da emoção e da comunicação 
humanas". Para Cedric, o impacto de ser tratado como totalmente humano, valorizado e amado por voluntários do teatro na prisão foi profundo.

A cor do amor é roxa para mim, então parece que estou respirando no ar sabor suco de uva o tempo todo. A prisão fede - mijo, merda, fedor, viritha e axilas, miséria, medo de desespero - mas tudo o que eu sinto aqui é o cheiro de uvas gordas e suculentas, tão roxas que são quase pretas.

Cedric muitas vezes se perguntou sobre o efeito que ele tem sobre os voluntários do Teatro na Prisão, a quem ele se refere como "belas almas". Ele teme que eles sejam "infectados" com o que ele sente que é a sua "falta". No momento da conclusão deste artigo, Cedric está escrevendo suas anotações de uma penitenciária de segurança máxima que ele descreve como "ainda na Idade das Trevas" e "despreocupada com a correção". Ele foi profundamente incrustrado para a barriga voraz da prisão neste tempo de Covid-19, garantindo um grau de separação ainda maior do que o habitual entre ele e sua família, amigos e programas criativos. Ele está incansavelmente preparado para permanecer não digerido.

Apesar do novo e desafiador contexto em que Cedric se encontra, longe da conectividade por meio do Teatro que abalou sua alma, o moldou e o sustentou nos últimos quatro anos, ele sabe que seu curso como pioneiro no Teatro na Prisão - e dentro das artes de forma mais ampla nas prisões - está definido. "O navio gira lentamente, mas gira" são suas palavras que reconhecem as complexidades - mas também as possibilidades de vida - que estão abertas a ele por meio da conexão humana e das artes na prisão. Apesar de estar em um lugar onde ele não tem confiança e no qual ele não pode ser vulnerável, e onde a única intimidade disponível para ele é a violência física, ele, no entanto, convence ativamente os presos frustrados em sua unidade para deixar de lado a agressão a favor da bondade e da compaixão, e para tentar transformar sua raiva e frustração em arte.

Aqui estão as reflexões de Cedric ao final desta conversa compartilhada: 
Nascemos como almas eternas; para aqueles de nós que estão encarcerados, algo, em algum lugar, deu errado. Essas pessoas do Teatro - tendo examinado a condição humana de todos os ângulos diferentes sabem melhor. Eles sabem que pessoas boas podem fazer coisas horríveis e por isso nos enxergam como humanos. Não somos diferentes deles, exceto por um conjunto diferente de circunstâncias. E desejamos ser vistos como bons. Portanto, neste mundo caótico onde a violência e a vileza se disfarçam de governantes, o Rei e a Rainha são a compaixão e a bondade. Ninguém de nós pode resistir muito tempo a um ataque de amor incondicional.

\section{Referências}

ABBOTT, J. H. In the Belly of the Beast: Letters from Prison. New York: Vintage Books, 1978.

ABRAMS, L., HUGHES, E., INDERBITZIN, M., \& MEEK, R. (Eds.) The Voluntary Sector in Prisons: Encouraging Personal and Institutional Change. London: Palgrave Studies, 2016.

ARMSTRONG, R. Trusting the untrustworthy: the theology, practice, and implications of faith-based volunteers' work with ex-prisoners. Studies in Christian Ethics, v. 27, n. 3, p. 299-317, 2014.

BREWSTER, L. The impact of prison arts programs on inmate attitudes and behavior: a quantitative evaluation. Justice Policy Journal, v. 11, n. 2, p. 1-28, 2014.

CHELIOTIS, L. (Ed.). The Arts of Imprisonment: Control, Resistance and Empowerment. Ashgate Publishing, 2012.

COHEN-CRUZ, J. Engaging Performance: Theatre as Call and Response. Florence: Routledge, 2010.

CREWE B., WARR, J., BENNETT, P., SMITH A. The emotional geography of prison life. Theoretical Criminology, v. 18, n. 1, p. 56-74, 2014.

CULLEN, F. The twelve people who saved rehabilitation: how the science of criminology made a difference. Criminology, v. 43, n. 1, p. 1-42, 2005.

DILLARD, A. The Writing Life. New York: Harper Perennial, 2013.

DWECK, C. Mindset: The New Psychology of Success. New York: Ballantine Books, 2006. 
FESETTE, N. \& LEVITT, B. Pedagogies of self-humanization: collaborating to engage trauma in the Phoenix Players Theatre Group. Teaching Artist Journal, v. 15, n. 3-4, p. 100-113, 2017.

FOUCAULT, M. Discipline and Punish: The Birth of the Prison. New York: Pantheon, 1977.

FOUCHÉ, C., \& LUNT, N. Nested mentoring relationship: reflections on a practice project for mentoring research capacity amongst social work practitioners. Journal of Social Work, v. 10, n. 4, p. 391-406, 2010.

FREIRE, P. Pedagogy of the Oppressed. New York: Continuum International Publishing Group, 1970.

GOFFMAN, E. Asylums: Essays on the social situation of mental patients and other inmates. New York: Anchor Books, 1961.

HAMER, K. Navigating boundaries, weaving worlds: U.S. practitioners' experiences of running theatre programmes in prisons. Cambridge, 2019. Thesis (Masters) University of Cambridge.

LIEBLING, A. Can human beings flourish in prison? PPT Lecture, London, 29 mai. 2012. Dísponivel em: <http://www.artsevidence.org.uk/media/uploads/evaluationdownloads/can-human-beings-flourish-in-prison---alison-liebling---may2012.pdf>

LUCAS, A. Prison Theatre and the Global Crisis of Incarceration. New York: Methuen Drama, 2020.

MORAN D. Carceral geography and the spatialities of prison visiting: visitation, recidivism, and hyperincarceration. Environment and Planning D: Society \& Space, v. 31, n. 1, p. 174-190, 2013.

SIMPSON, E., MORGAN, C., \& CAULFIELD, L. S. From the outside in: narratives of creative arts practitioners working in the criminal justice system. The Howard Journal of Criminal Justice, v. 58, n. 3, p. 384-403, 2019.

SMITH, C. What is a Person? Rethinking Humanity, Social Life, and the Moral Good from the Person Up. University of Chicago Press, 2010.

TEWKSBURY, R. \& COLLINS, S. Prison chapel volunteers, Federal Probation, v. 69, n. 1, p. 26-30, 2005.

TEWKSBURY, R. \& DABNEY, D. Prison volunteers: profiles, motivations, satisfaction. Journal of Offender Rehabilitation, v. 40, n. 1-2, p. 173-183, 2004.

TOFTELAND, C. The Keeper of the Keys. In: SHAILOR, J (Ed.) Performing New Lives: 
Prison Theater. London: Jessica Kingsley Publishers Ltd., 2011, p. 213-230.

TOMCZAK, P., \& ALBERTSON, K. Prisoner relationships with voluntary sector practitioners. The Howard Journal of Crime and Justice, v. 55, n. 1-2, p. 57-72, 2016.

TURNER, V. Liminal to liminoid, in play, flow, and ritual: an essay in comparative symbology. Mediações: Revista de Ciências Sociais, v. 17, n. 2, p. 214-257, 2012.

VAN DER KOLK, B. A. The Body Keeps the Score: Brain, Mind, and Body in the Healing of Trauma. New York, NY: Penguin Books, 2014.

VAN MAANEN, K. Miss Spent: A drama project for young women at the Josephine Butler Unit, HMP Downview. Evaluation Report. Disponivel em: <http://www.clinks.org/assets/ files/Miss\%20Spent\%20report\%20final.pdf>

ZELON, H. The Shakespeare redemption: Inmates in a Kentucky prison grapple with the truths of human existence. American Theatre v. 18, no. 8, p. 32-135,- 2001.

Recebido em: 06/12/2020

Aprovado em: 06/12/2020 